\title{
Modelling and Simulation of Methanol and Diesel Fuelled HCCI Engine for Improved Performance and Emission Characteristics
}

\author{
Suraj Randive ${ }^{1}$, Dhananjay Thombare ${ }^{2}$ \\ ${ }^{1,2}$ Automobile Engineering Department, Rajarambapu Institute of Technology, Rajaramnagar (Islampur), India
}

\begin{abstract}
Alcohol fuels are widely used for HCCI engine. In this study, Methanol is used in single cylinder engine as a premixed fuel with diesel in different compositions. Engine performance will improve in terms of thermal efficiency and emission. Intake charge within temperature range of $120^{\circ}-140^{\circ} \mathrm{c}$ gives good results for combustion, heat release \& pressure rise rate. Intake charge temperature and engine speed are dominant parameter which affects the performance and emission of the engine. Higher thermal efficiency \& lower emission can be achieved optimizing combustion duration and injection timing of both fuels which is also helpful for extending the operating range of HCCI engine.
\end{abstract}

Keywords: HCCI, BSFC, Methanol, Brake thermal efficiency, Emissions

\section{Introduction}

These days pollution is major issue due to variety of sources where I.C. Engine is the most significant contributor. Extensive uses of conventional fuels are leads to production of very toxic gases \& deteriorates environment badly. To overcome this, certain techniques are available called after treatments e.g. catalytic convertor, EGR etc. But it is always better to work at source level. So HCCI engine is one another option which helps to lower down the emission levels. HCCI Engine uses one highly active fuel i.e. methanol and one low reactive fuel i.e. diesel. If methanol and diesel are used in HCCI engine with different compositions at various speed and load conditions, one can identify its effect on thermal efficiency, BSFC \& emissions [1].

\section{Literature Survey}

Homogeneous charge compression ignition engines (HCCI) is a new research area implemented in practice to reduce the exhaust emission and enhancing the thermal efficiency of the engine. The principle of operation of this engine is it inducts the premixed fuel and air through port injector via Intake manifold which is homogeneous charge. Another fuel for e.g. diesel is injected at high pressure through main injector. Hence the combustion takes place spontaneously within shorter duration [2]. This results in to high pressure rise rate as well as heat release rate within combustion chamber. Chunhua zhang et al. (2015) reported that Homogeneous charge compression ignition (HCCI) technology is believed to be a promising one to be applied in both spark ignition (SI) and compression ignition (CI) engines in the near future [3]. However, some researchers such as Dong-bo Yang et al. (2011) were found that some challenges such as compromise combustion phase control, controlled auto-ignition, operating range, homogeneous charge preparation, cold start, emission of unburned hydrocarbon (UHC) and carbon monoxide (CO) need to be overcome for successful operation of HCCI engine. Extensive research on HCCI combustion with a homogeneous fuel-air mixture preparation is going on throughout the world (control strategy) [4].

\section{Engine Selection}

Diesel engine is suitable to convert in to HCCI engine because it has higher compression ratio and higher efficiency. There are many options available like single cylinder, multi cylinder; vertical, horizontal etc. but we have selected single cylinder four stroke water cooled diesel engine for modification. Table 1 gives the specifications of selected engine which is used for simulation of both the engines (CI as well as HCCI).

Table 1: Engine specification

\begin{tabular}{|c|c|}
\hline Type & PPW-5A \\
\hline No. of cylinder & Single cylinder \\
\hline Rated output (HP) & 5 \\
\hline Rated speed (rpm) & 1500 \\
\hline Bore (mm) & 87.5 \\
\hline Stroke (mm) & 80 \\
\hline Cubic capacity (CC) & 481 \\
\hline Compression Ratio & $16.7: 1$ \\
\hline Lubricant oil sump capacity & 1.3 Ltr. \\
\hline Specific fuel consumption (gm/kwhr) & 230 \\
\hline Net weight (kg) & 80 \\
\hline Method of cooling & Water cooled \\
\hline Method of starting & Hand starting \\
\hline
\end{tabular}

Table 2: Fuel Properties [5]

\begin{tabular}{|c|c|c|}
\hline Fuel property & Methanol & Diesel \\
\hline Formula & $\mathrm{CH}_{3} \mathrm{OH}$ & $\mathrm{C}_{12} \mathrm{H}_{23}$ \\
\hline Molecular weight & 32 & $180-200$ \\
\hline Oxygen content & $50 \%$ & 0 \\
\hline Stoichiometric air/fuel ratio & 6.45 & 14.5 \\
\hline Lower calorific value $(\mathrm{MJ} / \mathrm{kg})$ & 19.7 & 42.5 \\
\hline Freezing point $\left({ }^{0} \mathrm{C}\right)$ & -98 & -1 to -4 \\
\hline Boiling point $\left({ }^{0} \mathrm{C}\right)$ & 65 & $175-360$ \\
\hline Flash point $\left({ }^{0} \mathrm{C}\right)$ & 11 & 55 \\
\hline Auto-ignition temperature $\left({ }^{0} \mathrm{C}\right)$ & 465 & $220-260$ \\
\hline Research octane number & 108 & 25 \\
\hline Cetane number & 3 & $40-55$ \\
\hline
\end{tabular}




\section{International Journal of Science and Research (IJSR) \\ ISSN (Online): 2319-7064}

Index Copernicus Value (2013): 6.14 | Impact Factor (2015): 6.391

\section{GT-POWER simulation model}

For the simulation of HCCI engine we have used GTPOWER software which is best suitable one. Currently this software is used by almost all engine development industries. This software is useful for all segments of vehicle engines e.g. trucks, buses, cars, two wheelers, locomotives, lawn movers, racing engines, garden equipment etc. With help of this software one can model any advanced concepts with many components. The GT-SUITE environment also provides GT-POWER with a proven set of high-productivity features for pre and post-processing, DOE/optimization, neural networks and control modelling. This is specifically designed for both steady state and transient simulations. GTPOWER has long been recognized for its high degree of accuracy in predicting the behaviour of complex engine related phenomena at its core. The GT-POWER solver is based on the 1D solution fully unsteady nonlinear Navier Stokes equation [6].

\section{CI Engine simulation model}

The model represents various attributes such as inlet, inrun, inport, injector, cylinder, engine, Exval, Export etc. In this model injector is used for pressurised diesel injection having 6 holes. For connecting two pipes the attribute used is 'piperound'. Torque attribute is used for applying load on engine. In inlet attribute composition only fresh air is taken. Some of the object/ attribute were considered to be 'default' or 'ignore' which are not much effective in simulation.

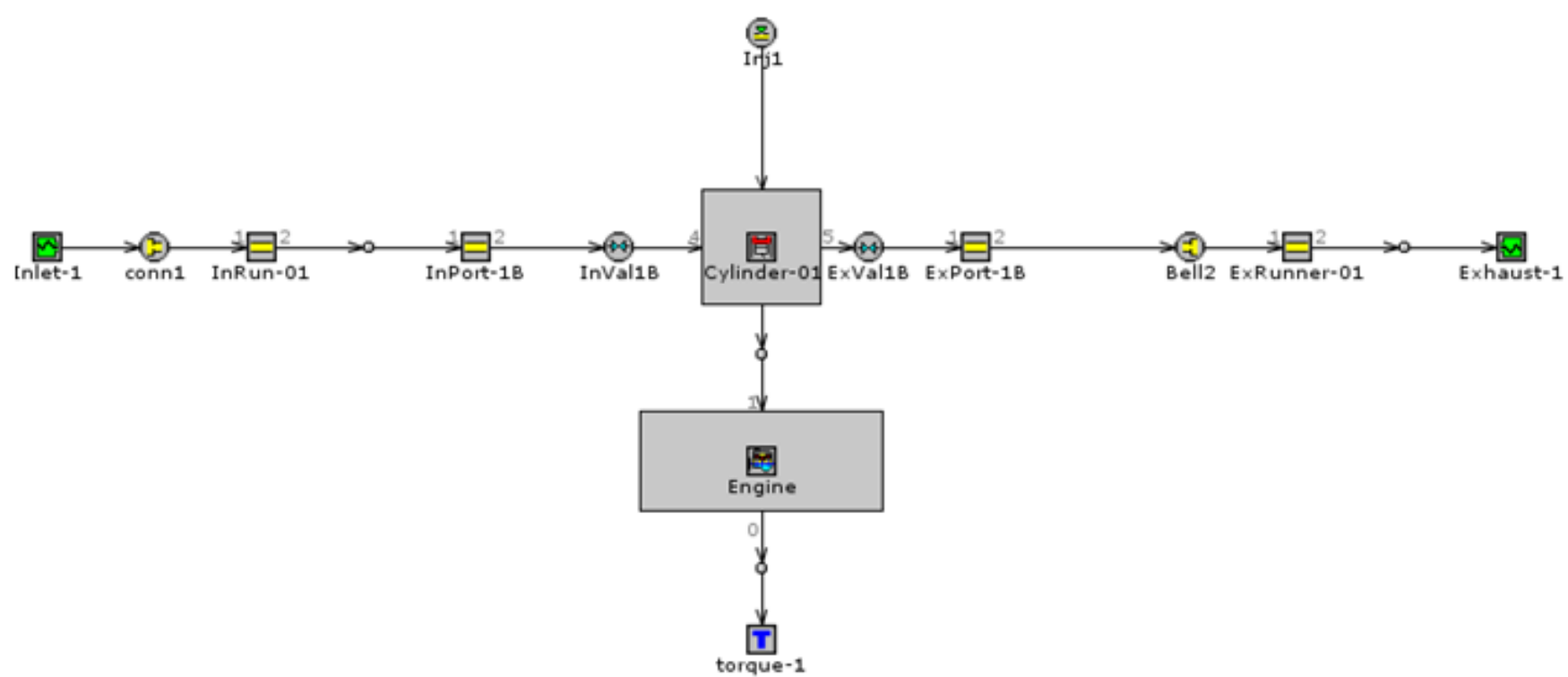

Figure 1: Single cylinder CI engine simulation model in GT-POWER

By using torque attribute engine has been loaded at 5 load intervals for e.g. (20, 40, 60, 80 and 100\%). Length of connecting rod of selected engine is $165 \mathrm{~mm}$. Also mass of fuel is varied on the basis of bsfc at all load conditions. BSFC at full load of our engine is $230 \mathrm{gm} / \mathrm{kw}-\mathrm{hr}$ [6].

\section{HCCI Engine Simulation Model}

In HCCI simulation model two injectors are used namely Injector1 and Injector2. Injector1 is used for port injection of methanol while Injector2 is used for diesel injection. Injection pressure is set to be $400 \mathrm{bar}$. Injector 1 is optimized at 5 to 8 degree crank angle BTDC of suction stroke for methanol injection and Injector2 is optimized to 24 degree BTDC of compression stroke for diesel injection. Other attributes/ objects were kept as same as CI Engine model [6]. 


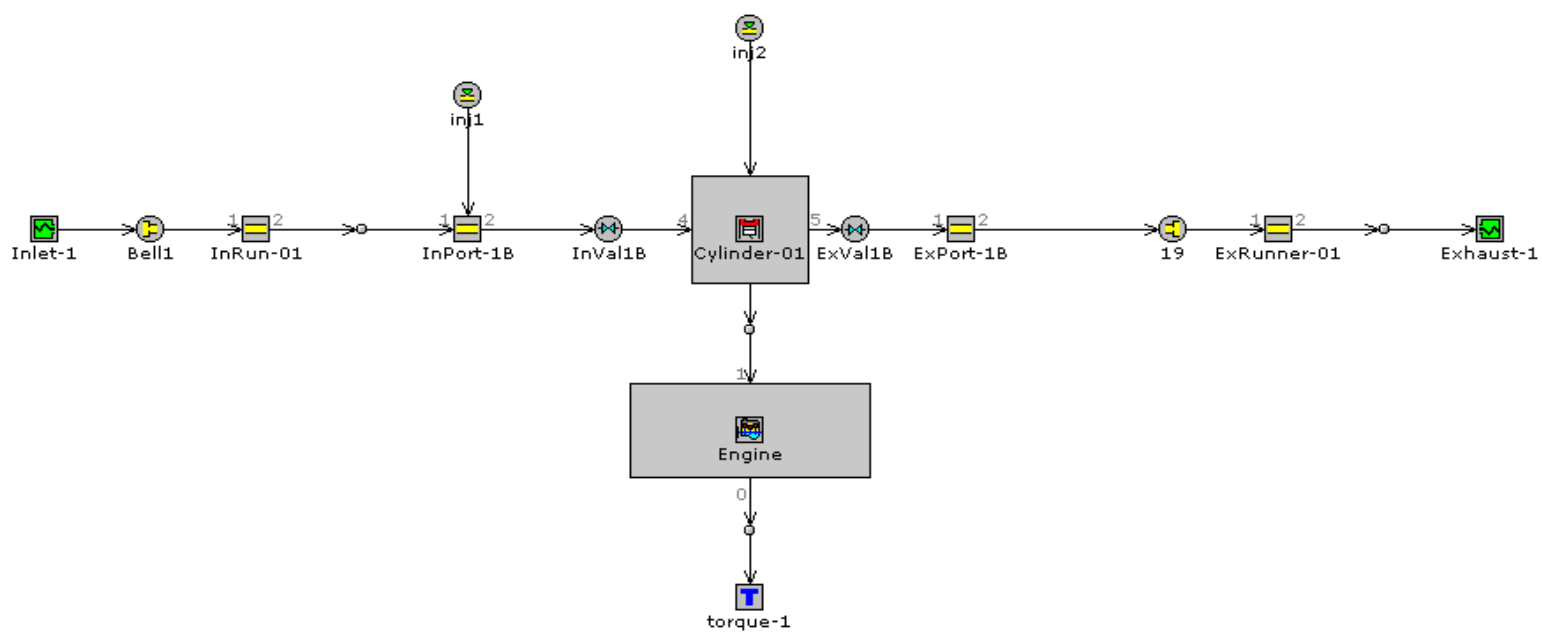

Figure 2: single cylinder HCCI engine simulation model in GT-POWER

\section{Results and Discussion}

\section{A. Performance plots}

Following Graph shown in fig. 3 has compared brake power vs load (\%) of both CI and HCCI engine in simulation.

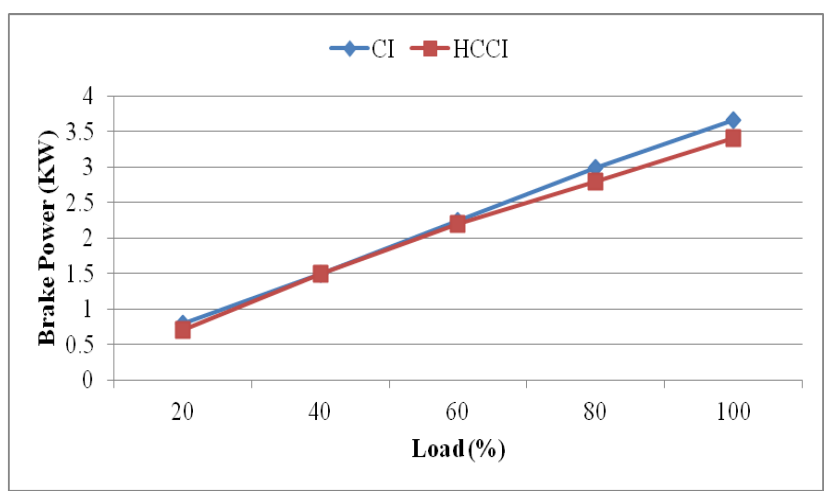

Figure 3: brake power (kW) VS load (\%)

From this plot we can conclude that brake power up to $60 \%$ load for both engine remains constant but from $60 \%$ load HCCI engine power slightly lowers down than CI engine. This is because of less quantity of diesel fuel which is replaced by renewable fuel (methanol).

Figure 4 represents brake thermal efficiency (\%) vs load (\%) of both CI and HCCI engine. Thermal efficiency of HCCI engine from $40 \%$ load gives better results because of increased total fuel consumption comparative to the conventional CI engine. While thermal efficiency of CI engine has gradual increment throughout all loads (21\% to $36.5 \%)$.

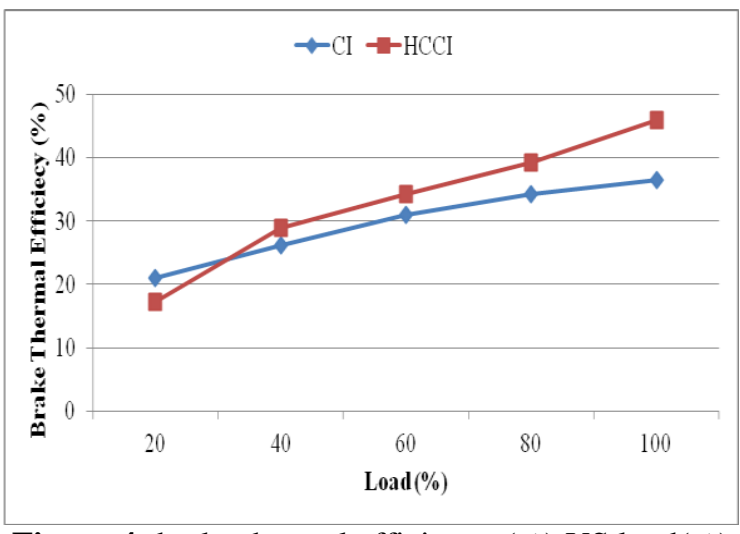

Figure 4: brake thermal efficiency (\%) VS load(\%)

Graph in fig. 5 shows the BSFC (gm/kwhr) vs load (\%) of both engines.

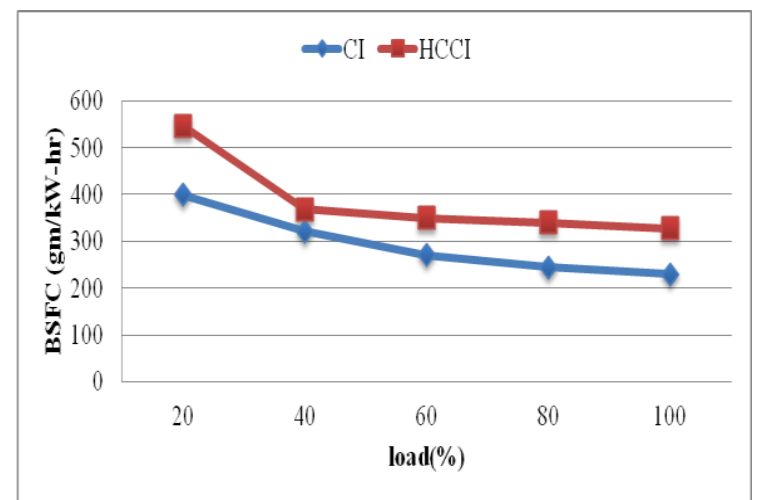

Figure 5: BSFC (gm/kW-hr) VS load (\%)

There is gradual decrement in bsfc of CI engine from $20 \%$ to $100 \%$ load (399.6 to $229.2 \mathrm{gm} / \mathrm{kw}-\mathrm{hr}$ ). But in case of HCCI engine there is sudden drop of bsfc from $20 \%$ to $40 \%$ further it maintains gradual decrement.

\section{B. Emission plots}

Graph in fig. 6 shows the HC emission (ppm) Vs \% load of engine. 


\section{International Journal of Science and Research (IJSR)}

ISSN (Online): 2319-7064

Index Copernicus Value (2013): 6.14 | Impact Factor (2015): 6.391

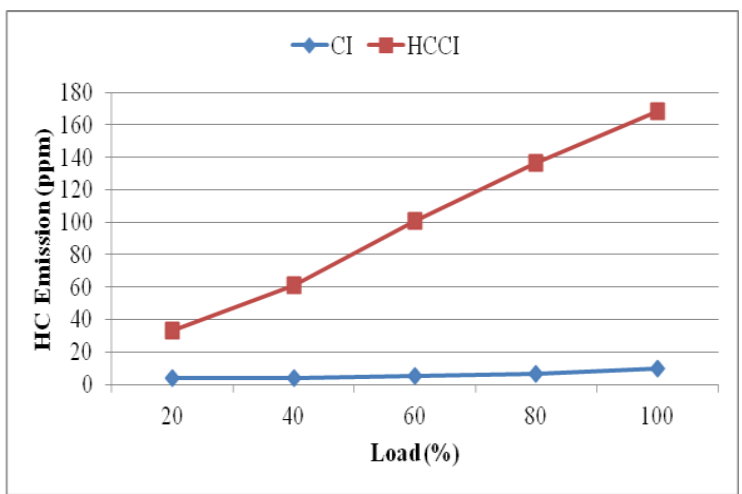

Figure 6: HC emission(ppm) VS load (\%)

For HCCI engine HC emission increases linearly with load on the engine increases (33.03ppm to $275.71 \mathrm{ppm}$ ) while in case of conventional CI engine, it remains constant throughout all loads (3.68 to $9.91 \mathrm{ppm})$.

Graph in fig. 7 shows CO Emission (ppm) Vs Load (\%) on engine.

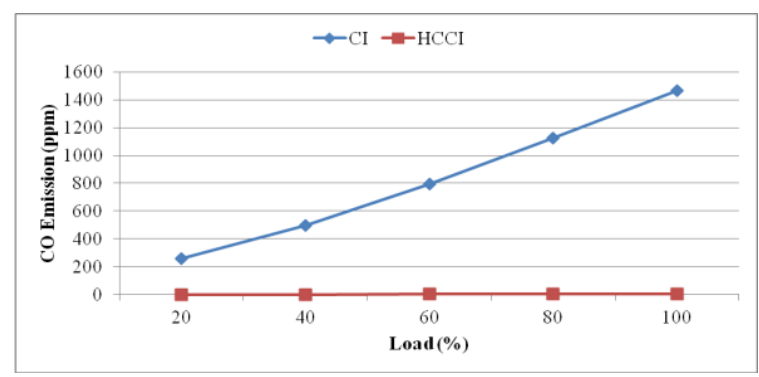

Figure 7: CO emission (ppm) VS load (\%)

\section{Conclusion}

1) Power output is not much affected by engine load in HCCI compare to $\mathrm{CI}$ engine.

2) Brake thermal efficiency of HCCI engine from $40 \%$ load gives better results than $\mathrm{CI}$ engine.

3) BSFC of HCCI engine is always found to be at higher level than conventional $\mathrm{CI}$ engine.

4) With increase of engine loads $\mathrm{HC}$ emission ( $\mathrm{ppm}$ ) of HCCI engine has increased drastically

5) $\mathrm{CO}$ emission (ppm) are quite lower (below $2 \mathrm{ppm}$ ).

\section{Future Scope}

The simulation can be carried out by considering the parameters such as in- cylinder pressure, heat release rate and multiple injection of diesel to improve the performance and emission characteristics of HCCI engine.

\section{References}

[1] P. TerrinBabu, P. R. Srivathsan, 2010, "Experimental Investigation on Performance and Emission Characteristics of Dual Fuel Split Injection of Ethanol and Diesel in CI engine", IEEE, 135-140.

[2] R. K. Maurya, A. Agarwal, 2014, "Experimental investigations of performance, combustion and emission characteristics of ethanol and methanol fueled HCCI engine", Fuel processing technology, 126, 30-48.
[3] Chunhua Zhang, Han Wu, 2015, "Combustion characteristics and performance of a methanol fueled homogenous charge compression ignition (HCCI) engine", Journal of the Energy Institute, Elsevier, 1-8.

[4] Dong-bo Yang, Zhi Wang, Jian-Xin Wang, Shi-jin Shuai, 2011, "Experimental study of fuel stratification for HCCI high load extension", Applied energy, 88, 2949-2954.

[5] http://www.methanol.org/methanolbasics/overview/how-is-methanol-made-.aspx (visited on 15 Feb 2016)

[6] http://www.gtisoft.com (visited on 1 March 2016)

\section{Author Profile}

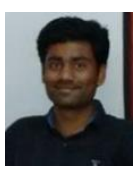

Randive Suraj doing $M-$ Tech in Automobile Engineering from Rajarambapu Institute of Technology, Sakharale, Maharashtra. He received B. E. Degree in Automobile Engineering from Shivaji University, Kolhapur in 2014. His area of research is I.C. engine, vehicle safety and chassis system.

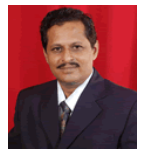

Thombare Dhananjay is working as professor in Rajarambapu Institute of Technology, Sakharale, Maharashtra. He is pursuing $\mathrm{Ph}$. D. from Shivaji University, Kolhapur. He received M.E. (Mech) in power engineering and B.E. in Automobile Engineering. He has teaching experience of 25years. His area of specialization is I.C. engine and Automobile Engineering. 